\title{
Risk of malignant change in ulcerative colitis
}

\author{
J. M. HINTON ${ }^{1}$ \\ From St. Mark's Hospital, London
}

EDITORIAL COMMENT This paper helps towards defining those groups of patients with colitis who have a serious risk of developing carcinoma subsequently. The identification of these high risk individuals helps in the clinical management in the follow up of this illness.

It is now certain that some patients with ulcerative colitis are more liable to develop a large bowel cancer than a normal person. It is therefore important to establish in which patients the risk occurs and to try and determine its magnitude. When large numbers of colitics with disease of varying extent and widely different duration of symptoms are considered the development of cancer is uncommon. In three big series the incidence lay between 3 and $4 \%$ (Slaney and Brooke; 1959, Nefzger and Acheson, 1963; Edwards and Truelove, 1964). It has been calculated by comparing death rates that in large series the cancer incidence is between seven and eleven times that to be expected in a matched general population (Goldgraber, Humphreys, Kirsner, and Palmer, 1958; de Dombal, Watts, Watkinson, and Goligher, 1966). However, it was established some years ago by Counsell and Dukes (1952) that amongst certain colitics the incidence of cancer could be much higher: in their series of consecutive surgical resections it was $11 \%$.

This paper has a dual intent, first to describe a series of cases from St. Mark's Hospital which provides some new and some confirmatory data, and second to assemble some of the clinically relevant information from the now extensive literature.

\section{THE ST. MARK'S SERIES}

During the 18 years 1947-64 32 patients with ulcerative colitis and histologically proven adenocarcinoma of the rectum or colon were seen at St. Mark's. Four other possible cases were excluded, three because the clinical and pathological evidence for ulcerative colitis was inadequate and the fourth because there was no histological evidence obtained for a clinically diagnosed cancer. In addition, during this period there was one case of squamous carcin-

\footnotetext{
${ }^{1}$ In receipt of a grant from the Medical Research Council.
}

oma of the anal canal and one of lymphosarcoma of the recto-sigmoid (Cornes, Smith, and Southwood, 1961) which are not included in the series. Of the patients in the series, 22 already had carcinoma at the time of referral to the hospital. Details of the individual cases are given in Table I.

\section{HIGH RISK COLITIS}

The factors known to affect the cancer incidence in colitis are the extent to which the colon is involved in the disease, the duration of the disease, and the age of the patient at the time of the onset of the colitis. It is the extent of the disease which seems to be all important, the other two factors acting only as modifying influences.

EXTENT OF COLITIS The effect of the extent of the inflammatory involvement of the colon can be looked at statistically in two ways. In Table II the extent of the disease in three series of colitics who have developed cancer is analysed. In Table III the incidence of cancer is analysed in relation to the extent of inflammatory involvement of the colon. It is important to remember when looking at Table III that the figures are being quoted to show the relative, not the absolute, incidence of cancer, for no allowance has been made for the duration of the colitis.

From these findings it seems most unlikely that patients with proctitis and proctosigmoiditis are at any greater risk of developing large bowel cancer than the normal population. The single cancer in MacDougall's series, as the author points out, could well have occurred by chance. Likewise it seems that although left-sided disease does increase the risk, it does so only slightly. In contrast it is quite clear that the cancer risk is increased by total involvement of the colon. It has been shown in one series (MacDougall, 1964a), by comparison with a matched general population, that the incidence of cancer 
TABLE I

CASES OF CANCER AND ULCERATIVE COLITIS ADMITTED TO ST. MARK'S HOSPITAL, 1947-64

\begin{tabular}{|c|c|c|c|c|c|c|c|c|c|}
\hline No. & Name & $\begin{array}{l}\text { Age at } \\
\text { Onset of } \\
\text { Colitis }(y r .)\end{array}$ & $\begin{array}{l}\text { Length } \\
\text { of } \\
\text { History } \\
(y r .)\end{array}$ & $\begin{array}{l}\text { Extent of } \\
\text { Colon } \\
\text { Involvement }\end{array}$ & $\begin{array}{l}\text { Year of } \\
\text { Diagnosis }\end{array}$ & $\begin{array}{l}\text { ? Secondaries } \\
\text { Present }\end{array}$ & Site of Carcinoma & $\begin{array}{l}\text { Grade of } \\
\text { Carcinoma } \\
\text { Dec }\end{array}$ & $\begin{array}{l}\text { Survival } \\
\text { Time } \\
\text { at } \\
\text { mber } 1964\end{array}$ \\
\hline 1 & E.S. & 39 & 17 & Total & 1947 & Yes & Transverse colon & High & $2 \mathrm{mth}$. \\
\hline 2 & H.S. & 35 & 20 & $?$ & 1947 & Yes & Rectum & Low & $14 \mathrm{yr}$. \\
\hline 3 & M.B. & 22 & 33 & $?$ & 1948 & Yes & Rectum & High & $6 \mathrm{mth}$. \\
\hline 4 & S.S. & 46 & 9 & Total & 1949 & Yes & Rectum & High & 2 wk. \\
\hline 5 & A.J. & 51 & 3 & $?$ & 1949 & Yes & Rectum & Average & 3 wk. \\
\hline 6 & E.S. & 23 & 38 & Total & 1949 & No & Splenic flexure & Low & $14 \mathrm{yr}$. \\
\hline 7 & L.P. & 38 & 13 & Extensive & 1950 & Yes & Rectum & High & $1 \mathrm{wk}$. \\
\hline 8 & O.D. & 19 & 18 & Extensive & 1951 & No & Transverse colon & High & \\
\hline & & & & & & & $\begin{array}{l}\text { Rectosigmoid } \times 2 \\
\text { Rectum } \times 2\end{array}$ & Low & $7 \mathrm{yr}$. \\
\hline 9 & W.F. & 32 & 13 & Total & 1952 & No & Transverse colon & Low & $12 \mathrm{yr}$. \\
\hline 10 & A.G. & 41 & 16 & Total & 1952 & No & $\begin{array}{l}\text { Caecum } \\
\text { Transverse colon } \\
\text { Splenic flexure } \\
\text { Descending }\end{array}$ & Average & $12 \mathrm{yr}$. \\
\hline 11 & L.B. & 38 & 27 & $?$ & 1953 & Yes & Rectum & Average & $9 \mathrm{mth}$. \\
\hline 12 & O.P. & 23 & 14 & $?$ & 1954 & Yes & Sigmoid & $?$ & $1 \mathrm{mth}$. \\
\hline 13 & R.T. & 44 & 10 & Total & 1954 & No & $\begin{array}{l}\text { Transverse } \\
\text { Colon }\end{array}$ & Low & $10 \mathrm{yr}$. \\
\hline 14 & V.S. & 17 & 16 & Total & 1954 & Yes & Splenic flexure & High & $3 \mathrm{mth}$. \\
\hline 15 & M.H. & 38 & 15 & Left side & 1954 & Yes & Rectum & High & $3 \mathrm{mth}$ \\
\hline 16 & J.P. & 20 & 9 & Total & 1955 & Yes & $\begin{array}{l}\text { Transverse colon } \\
\text { Rectum }\end{array}$ & High & $12 \mathrm{mth}$. \\
\hline 17 & M.P. & 35 & 20 & Total & 1955 & Yes & Descending colon & Low & $2 \mathrm{yr}$. \\
\hline 18 & D.J. & 21 & 20 & Total & 1955 & Yes & $\begin{array}{l}\text { Hepatic } \\
\text { Flexure }\end{array}$ & Low & $4 \mathrm{mth}$. \\
\hline 19 & D.S. & 29 & 35 & Total & 1957 & No & Descending colon & Low & $7 \mathrm{yr}$. \\
\hline 20 & J.B. & 33 & 11 & Total & 1958 & Yes & $\begin{array}{l}\text { Hepatic flexure } \\
\text { Sigmoid } \\
\text { Rectum }\end{array}$ & High & $1 \mathrm{wk}$. \\
\hline 21 & A.B. & 27 & 20 & Total & 1958 & No & $\begin{array}{l}\text { Transverse colon } \\
\text { Splenic flexure }\end{array}$ & High & $6 \mathrm{yr}$. \\
\hline 22 & L.A. & 8 & 26 & Extensive & 1958 & Yes & $\begin{array}{l}\text { Sigmoid } \\
\text { Rectum }\end{array}$ & High & $8 \mathrm{mth}$. \\
\hline 23 & R.D. & 18 & 45 & Total & 1960 & Yes & Sigmoid & Low & $2 \mathrm{yr}$. \\
\hline 24 & S.H. & 25 & 13 & Total & 1962 & No & Transverse colon & Low & $2 \mathrm{yr}$. \\
\hline 25 & T.P. & 27 & 18 & Total & 1962 & Yes & Rectum & Average & $1 \mathrm{mth}$. \\
\hline 26 & V.D. & 46 & 9 & Total & 1963 & No & Transverse colon & Average & $2 \mathrm{yr}$. \\
\hline 27 & C.F. & 13 & 13 & Total & 1964 & Yes & Recto-sigmoid & High & $4 \mathrm{mth}$. \\
\hline 28 & A.B. & 31 & 19 & Total & 1964 & No & Recto-sigmoid & Average & Less \\
\hline 29 & A.A. & 20 & 46 & Total & 1964 & Yes & Descending colon & & than one \\
\hline 30 & D.M. & 23 & 24 & Total & 1964 & $?$ & Recto-sigmoid & Low & year \\
\hline 31 & D.W. & 16 & 31 & Total & 1964 & No & Recto-sigmoid & Average & since \\
\hline 32 & L.P. & 27 & 24 & Total & 1964 & No & $\begin{array}{l}\text { Rectum } \\
\text { Sigmoid }\end{array}$ & Average & $\begin{array}{l}\text { operation } \\
\text { all alive }\end{array}$ \\
\hline
\end{tabular}

TABLE II

EXTENT OF COLITIS IN CANCER CASES

Series of Cases

\begin{tabular}{lll}
\hline St. Mark's & Edwards & MacDougall \\
Hospital & $\begin{array}{l}\text { and } \\
\text { (1965) }\end{array}$ & $\begin{array}{l}\text { Truelove } \\
\text { (1964) }\end{array}$ \\
&
\end{tabular}

Total and extensive ${ }^{2}$

Left-sided

Proctosigmoiditis

Totals

$\begin{array}{rrr}26 & 17 & 9 \\ 1 & 4 & 1 \\ 0 & 1 & 0 \\ 27 & 22 & 10\end{array}$

Proctosigmoiditis is colitis not extending proximal to sigmoid colon. Left-sided is colitis not extending proximal to the splenic flexure.

Extensive is colitis not extending proximal to the hepatic flexure.

Total colitis is colitis involving the whole colon.

${ }^{1}$ In five cases the extent was uncertain.

'In order to make the series comparable the total and extensive groups have been amalgamated. In the St. Mark's series 23 of the 26 cases in this group had total involvement of the colon.
TABLE III

INCIDENCE OF CANCER OCCURRING IN COLITIS OF DIFFERENT EXTENT

Series

\begin{tabular}{lcc} 
& $\begin{array}{c}\text { Edwards and } \\
\text { Truelove }(1964)\end{array}$ & MacDougall (1964a) \\
\hline Total and extensive & $17(7 \cdot 2 \%)$ & $9(4.6 \%)$ \\
Left-sided & 236 & 196 \\
Proctosigmoiditis & $4(1.47 \%)$ & $1(0.34 \%)$ \\
& $272(1.07 \%)$ & 291 \\
& $93(0 \%)$ & 132
\end{tabular}




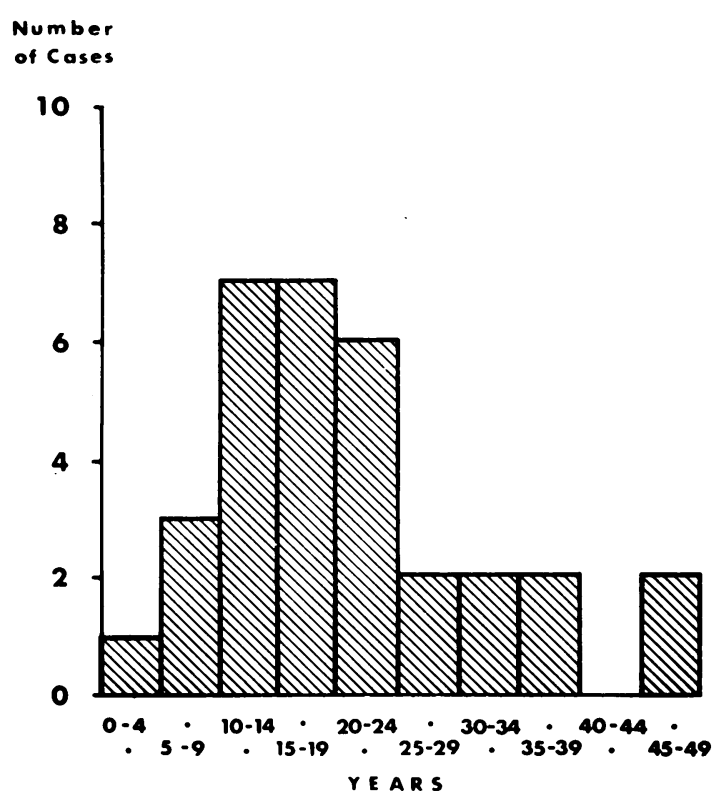

Fig. 1. Duration of colitis before diagnosis of carcinoma.

amongst patients with total colitis was 30 times the normal.

DURATION OF COLITIS The duration of the colitis up to the time of the diagnosis of carcinoma in the St. Mark's series is shown in Figure 1. It is clear that in all but a few cases the disease had been present for 10 years or more before the appearance of the cancer. More patients are found in the decade 10-19 years than in any other. This may be taken to indicate that, in susceptible patients, by the time the disease has been present for 10 years the cancer risk is becoming increasingly important. The data available on cumulative risk, although of necessity based on small numbers of cases and therefore to be applied with caution, support this view. It has been estimated (de Dombal et al., 1966) that whilst the cumulative risk at 10 years is only $5 \%$, over the next decade it rises at an increasing rate to $25 \%$ at 20 years and thereafter even more rapidly at $6 \%$ per annum.

AGE OF ONSET OF COLITIS There is a clinical impression that those who develop ulcerative colitis when young are more likely to suffer the complication of malignancy. MacDougall (1964b) has demonstrated one reason for this impression. He showed that, in a comparison between two groups of patients with total colitis of at least 10 years' duration, those whose colitis began before the age of 25 years had twice the cancer incidence of those whose colitis developed after this age. Another reason is that there is a higher incidence of total involvement of the colon amongst children with colitis than in adults. An analysis of the four paediatric series which give data on this point is shown in Table IV. Thus a higher proportion of children are at risk. There is also a natural tendency to postpone colectomy in children for as long as possible, in this way increasing their chances of developing cancer because of the effect of the duration of the disease.

\section{PATHOLOGY}

There are various aspects of the pathology of the development of carcinoma in colitis that are clinically relevant. The most important is that the whole colon is at risk. That this is so is demonstrated in two ways: the occurrence of multiple carcinomata and the development of carcinomata in the rectal stump after ileo-rectal anastomosis. In the St. Mark's series there were seven cases $(22 \%)$ with more than

\section{TABLE IV}

PROPORTION OF CASES OF TOTAL COLITIS IN PAEDIATRIC SERIES Series

Percentage of Cases of Total Colitis

Lagercrantz (1949)

King, Lindner, and Pollard (1959)

Hijmans and Enzer (1962)

Platt, Schl ssinger, and Benson (1960)

Edwards and Truelove (all age groups) (1964)

67
63
49
30
34

one cancer. In five of these multiple carcinomata were present at the time of diagnosis and in two a second carcinoma developed in defunctioned bowel. Multiple carcinomata have been found in varying proportions in other series: Edling and Ecklöf (1961) $5 \%$, Bargen and Gage (1960) $24 \%$, Goldgraber and Kirsner (1964) $42 \%$. In a series of 237 cases undergoing ileo-rectal anastomosis it has been shown (MacDougall, 1964a) that whilst over a variable period of follow-up only five rectal cancers occurred, this was 65 times the number of cancers to be expected in a comparable non-colitic population. Manifestly complete prophylaxis can only be obtained by total proctocolectomy. Nevertheless, as will be argued later, ileo-rectal anastomosis may be indicated in some instances.

Strictures fall into two categories as far as the cancer risk is concerned. Those which develop soon after a bad attack are merely a manifestation of severe disease. In a recent series, despite a high incidence $(11.2 \%)$ of strictures, in none was a carcinoma found and the point was made that in the majority of cases the colitis was of short duration 
TABLE V

PERCENTAGE DISTRIBUTION OF COLONIC CANCER

\begin{tabular}{lccccc} 
& No. of Cases & Colon $(\%)$ & & $\begin{array}{c}\text { Rectum and } \\
\text { Sigmoid (\%) }\end{array}$ \\
\cline { 3 - 5 } & & Ascending & Transverse & Descending \\
\hline Colitics & 379 & $16 \cdot 4$ & $25 \cdot 9$ & $10 \cdot 3$ & $47 \cdot 4$ \\
All series & 43 & 2 & 35 & 12 & 51 \\
St. Mark's Hospital (1965) & 6,277 & 10.9 & 8.5 & $4 \cdot 5$
\end{tabular}

(de Dombal et al., 1966). In contrast others have found a definite association between stricture and carcinoma (Slaney and Brooke, 1959; Edwards and Truelove, 1964). In the St. Mark's series 10 cancers were in rectal or sigmoid strictures. In colitics known to be at risk the development of a stricture should be regarded as suggesting malignant change.

It was once thought that pseudo-polypi represented pre-cancerous change (Bacon, Lin Min, Carroll, Cates, Villalba, and McGregor, 1956). It is now generally accepted that they have no causal relationship with cancer (Edwards and Truelove, 1964; de Dombal et al., 1966). Pseudo-polypi occur in association with severe disease, and this in turn usually involves the whole of the colon. Patients with total colitis are the ones liable to develop cancer. But cancer can also occur in colitics who do not have pseudo-polypi: in the St. Mark's series these were the majority.

The distribution of cancers around the colon in colitics is of both theoretical and practical importance. It can be seen from Table V, compiled from the data collected by Langman (1966), that, compared with the general population, there are relatively fewer carcinomata in the rectum and sigmoid and more in the transverse colon in colitics. As the rectum is almost invariably involved in colitis the reverse might be expected. Taken in conjunction with the fact that localized proctitis does not increase the risk of malignant change this suggests that there is something different about total colitis as far as the induction of cancer is concerned. This could be qualitative or quantitative. It is perhaps significant that in total colitis the transverse colon is frequently the part that undergoes the most extensive ulceration in a severe attack. From a practical standpoint, as about one quarter of the cancers occur in the transverse colon, it is one of the sites to watch for malignant change.

\section{DIAGNOSIS}

In the St. Mark's series the commonest presenting symptoms of a patient with a developing cancer were those of colitis either in continuous form or as an exacerbation (Table VI). Two symptoms helped in the distinction between a cancer and an exacerbation of colitis: abdominal pain, of a type unrelated to defaecation, and constipation. Unfortunately these are both rather late symptoms of cancer: the five patients with constipation lived only a short time.

The St. Mark's series also shows that in about $40 \%$ of the cases the carcinoma will be within reach of the sigmoidoscope and the diagnosis can therefore be

TABLE VI

PRESENTING SYMPTOMS OF CARCINOMA IN 32 CASES OF ULCERATIVE COLITIS

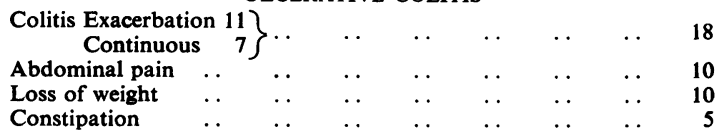

made certain by biopsy. Nevertheless in the majority of patients the diagnosis can only be made with the aid of radiology. The double-contrast technique is essential if small lesions are to be recognized. Even so the detection of small malignant plaques and cancerous strictures is often difficult in a colon already distorted by colitis.

Almost as misleading in a different way is the patient who has made a good functional recovery after total involvement of the colon. A barium enema performed at an earlier stage of the disease may be the only clinical evidence of past total colitis in a patient who subsequently develops cancer.

It is also important to avoid mistaking an inflammatory stricture in colonic Crohn's disease for malignancy in ulcerative colitis for this may lead to an unnecessary colectomy, there being, as yet, no evidence of increased risk of malignancy in colonic Crohn's disease.

\section{PROGNOSIS}

The prognosis of colitic cancers is generally regarded as being very bad. Michener, Gage, Sauer, and Stickler, (1961) found that of 46 colitics in whom the disease began under the age of 15 years and who subsequently developed cancer, only six $(13 \%)$ were alive five years later. Slaney and Brooke (1959), from a review of the literature, give a five-year survival figure of $18.6 \%$. However, Bargen and Gage (1960) 
find a five-year survival rate of $76 \%$. This figure is not directly comparable with the others since it is only for patients who have had a resection for cancer in colitis. Of the 178 patients they review, only 101 underwent resection so that the comparable overall figure would therefore be lower.

In the St. Mark's series the five-year survival figure for all the patients with colitic cancers is $40 \%$. As is to be expected this is related to the histological grading of the malignancy. Half the cases were of average or low-grade malignancy and amongst these the five-years survival was $75 \%$.

There are no survival figures available for carcinoma of the colon and rectum combined in the general population. However, the figures for segments of the large bowel suggest that there is little difference between rectum and colon. It has been shown (Bussey, 1963) that for cancer of the rectum in the general population the five-year survival figures are respectively $77 \%, 51 \%$, and $29 \%$ for low, average, and high-grade tumours, and the overall figure is $58 \%$. Whilst the cancer in figures for colitis are based on small numbers and a comparison with rectal cancers is not entirely satisfactory, it is clear that when divided according to histological grading the prognosis of cancers in colitis is not far different from the normal. The lower overall figure amongst colitics is due to the higher proportion of patients with high-grade malignancy, $50 \%$ as opposed to $20 \%$ in the general population (Dukes and Bussey, 1958). These findings are obviously of importance in assessing the prognosis in the individual case.

\section{PROPHYLAXIS}

The majority of patients with total colitis have sufficiently disabling symptoms to warrant colectomy before they have had the disease for 10 years. There remains a small, but with improvements in medical treatment a probably increasing, number of patients with total colitis and minimal symptoms. The management of these patients presents a problem. On the one hand it has been argued that all patients with total colitis should have a prophylactic colectomy both because of the risk of cancer and of the risks of other complications. But it may also be argued that it is wrong to deprive a patient of his colon for many years when it is not absolutely necessary. Quite apart from this, if relatively symptom free, he will not be willing to undergo the operation.

The alternative course is to follow up carefully all patients with total colitis and this will require regular barium enemas. This also poses problems. The double-contrast enema on the unprepared patient (Young, 1963), which is so satisfactory for displaying the inflammatory mucosal lesions, is inadequate for excluding carcinomata. Good preparation of the colon is required. Unfortunately this may precipitate a relapse. Secondly if a barium enema is done once a year a developing cancer may not be recognized sufficiently early for successful removal. If the examination is done every six months it is unlikely to be tolerated by the patient and it will also involve excessive irradiation.

There is a possibility that help may come from the pathologist in the future. There are certain histological changes in the rectal mucosa in colitics with cancer that may be regarded as premalignant. These changes are also found on rectal biopsy in patients with total colitis who have not yet developed a cancer (Morson, 1966). If a time scale can be established for the relationship between these premalignant changes and the development of invasive cancer then the regular examination of rectal biopsies could become clinically very valuable.

A compromise scheme for prophylaxis is as follows. First, all patients with total colitis when first seen should have the question of prophylactic surgery considered in the light of factors such as length of history, frequency of exacerbations, residual symptoms, other complications, and an assessment of the personal and social situation. Secondly all patients with total colitis who do not have surgery, and all who have an ileo-rectal anastomosis, should be kept under regular supervision. In patients who have had the disease for several years an exacerbation after a long period of remission should be regarded as possibly due to malignancy. Thirdly, once a patient with total colitis has had the disease for about 10 years prophylactic surgery because of the risk of cancer should be reconsidered, especially in the younger patient. Total proctocolectomy and ileostomy is the treatment of choice because the cancer risk involves the whole of the large bowel. With patients who are relatively free of symptoms it may be necessary to discuss the problem of the dangers of malignancy and to consider ileo-rectal anastomosis as an alternative procedure. The area of bowel at risk can at least then be kept under observation relatively easily. If operation is still not carried out then careful supervision must continue. In such a patient an exacerbation or chronic disease which responds badly to medical treatment should be regarded as indicating the possibility of malignant change.

\section{SUMMARY}

A series of 32 cases of large bowel carcinoma occurring in patients with ulcerative colitis is analysed. From this series and from a review of the literature certain clinically important facts emerge. It is con- 
cluded that total or extensive involvement of the colon by the inflammatory process is the major factor predisposing to the development of cancer. The risk increases progressively with time and is becoming of definite clinical importance when the disease has been present for 10 years. The risk is further increased when the colitis begins in childhood and reasons for this are suggested. The evidence for the whole of the large bowel being at risk is considered and the clinical and theoretical relevance of the altered distribution of cancers in the colon in colitis is discussed. This series proved to have a better prognosis than is often the case: $40 \%$ at five years. The relationship between prognosis and histological grading in these colitics is analysed. A regime for the management of colitics who are liable to develop cancer is proposed.

I am grateful to the surgeons at St. Mark's Hospital for allowing me to study their cases and to Dr. F.Avery Jones and Dr. J. E. Lennard-Jones for help and advice. Some of the findings in this paper were first presented to the Section of Proctology of the Royal Society of Medicine in January 1966.

\section{REFERENCES}

Bacon, H. E., Lin Min Ou Yang, Carroll, P. T., Cates, B. A., Villalba, G., and McGregor, R. A. (1956). Non-specific ulcerative colitis, with reference to mortality, morbidity, complications and longterm survival following colectomy. Amer. J. Surg., 92, 688-695.

Bargen, J. A., and Gage, R. P. (1960). Carcinoma and ulcerative colitis: prognosis. Gastroenterology, 39, 385-393.

Bussey, H. J. R. (1963). The long-term results of surgical treatment of cancer of the rectum. Proc. roy. Soc. Med., 56, 494-496.

Cornes, J. S., Smith, J. C., and Southwood, W. F. W. (1961). Lymphosarcoma in chronic ulcerative colitis. Brit. J. Surg., 49, 50-53.
Counsell, P. B., and Dukes, C. E. (1952). The association of chronic ulcerative colitis and carcinoma of the rectum and colon. Ibid., 39,485-495.

de Dombal, F. T., Watts, J. McK., Watkinson, G., and Goligher, J. C. (1966). Local complications of ulcerative colitis: stricture, pseudopolyposis, and carcinoma of colon and rectum. Brit. med. J., 1, 1442-1447.

Dukes, C. E., and Bussey, H. J. R. (1958). The spread of rectal cancer and its effect on prognosis. Brit. J. Cancer, 12, 309-320.

Edling, N. P. G., and Ecklöf, O. (1961). Distribution of malignancy in ulcerative colitis. Gastroenterology, 41, 465-466.

Edwards, F. C., and Truelove, S. C. (1964). The course and prognosis of ulcerative colitis: Pt. IV. Carcinoma of the colon. Gut, 5, 1-22.

Goldgraber, M. B., Humphreys, E. M., Kirsner, J. B., and Palmer, W. L. (1958). Carcinoma and ulcerative colitis: a clinicalpathologic study. II. Statistical analysis. Gastroenterology, 34, 840-846.

- , and Kirsner, J. B. (1964). Carcinoma of the colon in ulcerative Colitis. Cancer (Philad.), 17, 657-665.

Hijmans, J. C., and Enzer, N. B. (1962). Ulcerative colitis in childhood: a study of 43 cases. Pediatrics, 29, 389-403.

King, R. C., Lindner, A. E., and Pollard, H. M., (1959). Chronic ulcerative colitis in childhood. Arch. Dis. Child., 34, 257-261.

Lagercrantz, R. (1949). Ulcerative colitis in children. Acta paediat. (Uppsala), suppl. 75, 89-151.

Langman, M. J. S. (1966). Epidemiology of cancer of the large intestine. Proc. roy. Soc. Med., 59, 132-134.

MacDougall, I. P. M. (1964a). The cancer risk in ulcerative colitis. Lancet, 2, 655-658.

- (1964b). Clinical identification of those cases of ulcerative colitis most likely to develop cancer of the bowel. Dis. Colon Rect., 7, 447-450.

Michener, W. M., Gage, R. P., Sauer, W. G., and Stickler, G. B. (1961). The prognosis of chronic ulcerative colitis in children. New Engl. J. Med., 265, 1075-1079.

Morson, B. C. (1966). Personal communication.

Nefzger, M. D., and Acheson, E. D. (1963). Ulcerative colitis in United States Army in 1944. Gut, 4, 183-192.

Platt, J. W., Schlesinger, B. E., and Benson, P. F. (1960). Ulcerative colitis in childhood: a study of its natural history. Quart. $J$. Med., 29, 257-277.

Slaney, G., and Brooke, B. N. (1959). Cancer in ulcerative colitis. Lancet, 2, 694-698.

Young, A. C. (1963). The 'instant' barium enema in proctocolitis. Proc. roy. Soc. Med., 56, $491-494$. 